\title{
Massive Open Online Courses for Africa by Africa
}

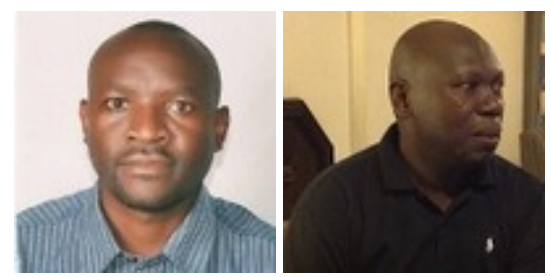

Benedict Oyo and Billy Mathias Kalema Tshwane University of Technology, South Africa

\section{Abstract}

Africa is known for inadequate access to all sorts of human needs including health, education, food, shelter, transport, security, and energy. Before the emergence of massive open online courses (MOOCs), open access to higher education (HE) was exclusive of Africa. However, as a generally affordable method of post-secondary education delivery, MOOCs place the developing countries at the centre of universal access to HE. This paper provides the strategy for MOOC implementation in the context of limited resources in Africa. The strategy is clustered under five baseline requirements: national accredited MOOC curriculum, electronic content development, development of an online and offline eLearning platform, establishment and funding of MOOC coordination units at public HEIs, and establishment of MOOC access hubs at strategic locations. Emerging from this paper is the insight that a new era of universal access to HE in Africa is achievable through MOOCs only if initial requirements are met by the respective governments.

Keywords: MOOCs; higher education; eLearning; African governments; low bandwidth 


\section{Introduction}

The shared vision of Africa seems to be a poverty free people in the next two decades. This is implied by the respective African countries' vision statements, such as Rwanda's vision 2020 that aims to transform Rwanda into a middle income nation with healthier, educated, and generally more prosperous people, while Nigeria's vision 2020 seeks to position Nigeria as one of the top twenty economies in the world. Similarly, Kenya's vision 2030 seeks to create a globally competitive and prosperous nation with a high quality of life. South Africa's vision is to eliminate poverty and reduce inequality by 2030, and Uganda's vision is to transform the Ugandan society from a peasant to a modern, prosperous, and competitive upper middle-income country by 2040. This shared vision may, however, not be possible with the current largely illiterate society and weak science and technology environments that can only be strengthened by open HE training. This paper therefore seeks to demonstrate that a good design of MOOCs could widen $\mathrm{HE}$ access to disadvantaged students in Africa thereby promoting holistic economic emancipation.

Given the pervasiveness of information technologies in education, researchers and governments are beginning to visualise a paradigm shift towards higher education for all, anytime and anywhere (J ordan, 2014; Economides, 2013; Materu, 2007). This is the type of education that MOOCs can deliver. MOOC is a model of educational delivery that is, to varying degrees, massive (no limit on enrolment), open (optional admission requirements and usually no tuition), online, and a course with defined curriculum leading to an award of a completion certificate (EDUCAUSE, 2013). The "open" aspect has also been argued from the perspective of openness of learning content and learning process, giving rise to two major forms of MOOCs: xMOOCs and cMOOCs. xMOOCs are structured similarly to traditional online higher education courses in which students watch video lectures, read assigned material, participate in online discussions and forums, and complete quizzes and tests on the course material, while cMOOCs are based on connectivist pedagogy allowing learners to construct the learning process through their interactions (Grünewald et al., 2013; Rodriguez, 2013). In this paper we emphasise xMOOCs because they are easily adoptable from the traditional face-to-face and/or blended learning settings.

MOOCs have shown themselves to be an effective innovation, helping uncover new best practices that could be used in other online, face-to-face, or blended pedagogies. Perhaps MOOCs' most important contribution to date has been to raise important questions and spark essential conversations about curriculum design, accreditation, what constitutes a valid learning experience, and who has access to higher education (EDUCAUSE, 2013). If African governments commit to MOOCs through solid curricula, instructor training and electronic content development and content delivery platforms, and provision of modern access hubs, public HEIs are likely to support open access agenda and even seek additional funding from development partners to strengthen their niche. There is no doubt that MOOCs are suitable for Africa since they reduce the need for costly large lecture rooms, eliminate student accommodation and transportation 
costs, and, above all, enable massive access with tuition fees waived or set relatively low and within reach of poor students.

\section{The Case for MOOCs in Africa}

The argument for MOOCs in Africa is driven by the need for affordable HE access solutions. Access to HE in Africa is a long standing problem, stemming from the ivory tower era where access was only for the elite state funded students and the majority of students dropping out of education into low skilled or casual employment. Following the enactment of educational laws for provision of private higher education during the early 1990s, Africa has witnessed sporadic increase in access to higher education through both the private window in public universities and private institutions. As a result, the mode of access became more flexible for students preferring to study during day, evening, or weekends as well as those on distance programmes. Despite these developments, the majority of students with minimum entry grades in Africa still cannot access higher education due to poverty (Materu, 2007; Osokoya, 2007).

Africa is not only a silent player but also a silent spectator in the ongoing MOOC revolution. Perhaps the silence of Africa is justified given the prevailing reality in the developed world where MOOCs are failing to reach disadvantaged students who would not ordinarily have access to educational opportunities (Emanuel, 2013). On the other hand, the fact that MOOCs are intended for mass enrolment with usually no tuition required from the students is more appealing to developing countries than the developed countries. A key question to pose at this point is: why are MOOCs not featuring in Africa? This paper does not merely attempt to answer the latter question but a more strategic question, that is, how should MOOCs be designed for developing countries such as those in Africa?

Throughout the world, the cost of education increases by the level undertaken. Lewin (2004) reports that the cost of secondary education per pupil in sub Saharan Africa is five times that of primary education. The net effect of this reality is reflected by larger government funding for primary education in Africa compared to lukewarm government support to secondary education and subsequently HE. It seems therefore possible for African governments to reconsider financing $\mathrm{HE}$ if affordable access solutions are available. MOOCs present an affordable post-secondary education delivery method for the majority poor/needy students in Africa. Indeed MOOCs could eliminate Africa's nightmare of large school dropouts after secondary school education. Figure 1 depicts the relevance of MOOCs in enabling open access to HE while simultaneously eliminating post-secondary school dropouts/ exclusions. 


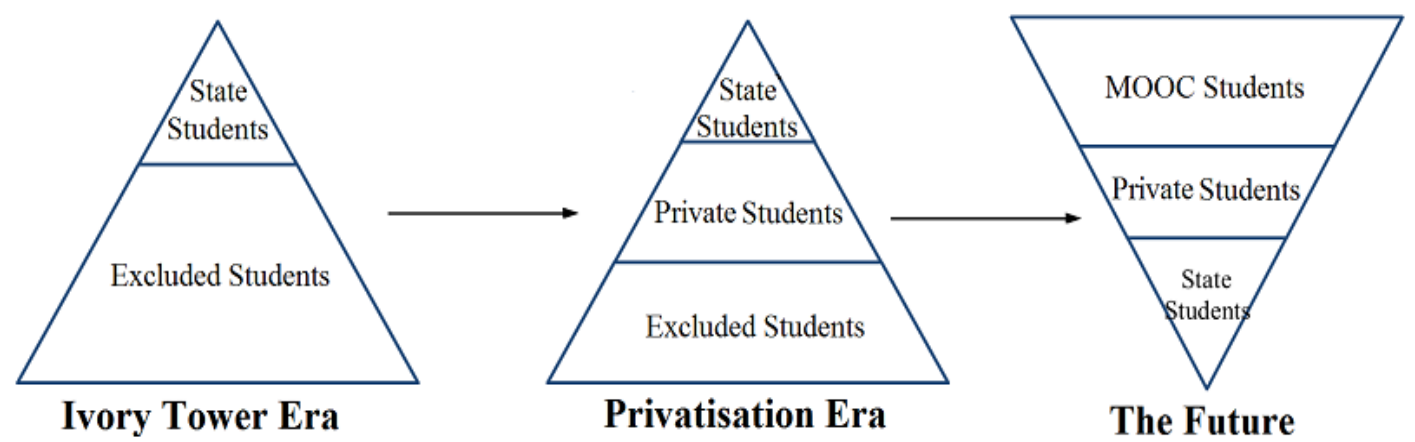

Figure 1. Perspectives of higher education access in Africa: past, present and future.

As illustrated in Figure 1, the challenge of exclusions from HE training has persisted since the inception of HE in Africa and could only be eliminated by adopting MOOCs. In the past, students in Africa were excluded from HE training due to the ivory tower mentality that restricted access to only the elite society. The current transition in HE access trajectory through massive privatisation, though highly commended for expanding access, has excluded a large section of the needy/ poor students in Africa who cannot afford tuition (Osokoya, 2007; Materu, 2007). Now is the time therefore to investigate other HE access options such as MOOCs that are exclusive of the financial abilities of students. Providing a design of MOOCs in the context of Africa's situations, such as low internet bandwidth, weak professional competencies, and lack of political support, is the first step in ensuring a future of open HE access in Africa. This future underpinned by MOOCs resonates with Africa's educational vision of affordable HE access as a means of eliminating poverty through development of human resource capacity (Pityana, 2009).

\section{Strategy for MOOCs in Africa}

Africa in the current state is not ready for MOOCs due to a number of factors, including but not limited to weak instructors' readiness for digital education, scarce locally developed electronic content, low bandwidth Internet connectivity, limited access to computers, computer illiteracy of HE entrants, and frequent electricity blackouts. In light of these challenges, Africa's approach to MOOCs must be rooted in government support at the initial stages while building capacity of the participating HEIs to independently manage their MOOC programmes. At the initiation stage, the African governments should focus on formation and funding of national coordination secretariat, content development and programme accreditation, content delivery mechanism, provision of access to computers and Internet, and funding of MOOC coordination departments in public HEIs. The details of this strategy follow. 


\section{Formation of the National MOOC Coordination Secretariat}

MOOCs present a rare opportunity for African governments to provide universal access to HE without direct dependence on international grants or loans. The fruits of MOOCs could turn sour right from the outset if MOOCs are not properly coordinated in Africa. The respective African governments are therefore obliged to form a national MOOC secretariat tasked with initiating and regulating the MOOC agenda. This will involve activities including spearheading curriculum development and accreditation, electronic content development, development of an online and offline eLearning platform, formation of MOOC access hubs for needy students, and coordination of MOOC implementation in collaboration with MOOC departments in participating HEIs.

\section{Programme Accreditation and Content Development}

The pioneer MOOC programmes, such as Coursera, edX, Udacity, and Udemy, have independent content delivery platforms for video lectures, multimedia instruction, online forums, and online tests/quizzes. African HEIs already have accredited programmes delivered under the traditional lecture method. These same programmes will be pooled and digitised by involving top academicians coordinated by a national MOOC secretariat. The resultant MOOC programmes will then be accredited. This will ensure that quality assurance issues are addressed from the onset without compromising national and international programme standards. Future content reviews and improvements should be coordinated by the national MOOC secretariat in collaboration with implementing institutions and guided by a consolidated continuous quality improvement framework.

\section{Online and Offline eLearning Platform}

Fully functional eLearning platforms are not common in African HEIs. More often than not, eLearning platforms are only operational in certain departments, such as computing, engineering and education, where computers and Internet are most used. Eka (2010) reports of wasted externally funded eLearning resources in African universities due to ineffective implementation and lack of sustained commitment by university administrators. Therefore, successful adoption of MOOCs by African HEIs requires an eLearning platform developed and maintained by a third party which in this case is the MOOC secretariat. The participating institutions would then customise their environments according to their preferences, while supporting their students learning. The same institutional eLearning environment could be used to connect students on traditional programmes with their MOOC counterparts. At the same time, the eLearning platform should have an offline function to cater for places with slow or no Internet connection. Details on the aspect of offline access is given in the next section.

\section{Ubiquitous Access to Computers and Internet}

Access to computers and access to Internet are two separate issues in Africa, with the former more abundantly available than the latter. Within education, the introduction of 
computer studies in secondary school curriculum is boosting access to computers in many parts of Africa. In Uganda, for instance, all public secondary schools irrespective of their location now have access to state-of-the-art networked computers (Oyo \& Williams, 2014). Rwanda and Nigeria are unique cases with access to computers both in schools as well as through ICT buses (mobile Telecentres or Internet units). The latest report by the government of Rwanda indicates that students and the general public can now access Internet through 94 mobile Telecentres across all the 30 districts (Republic of Rwanda, 2014). Similarly, the mobile Internet units in Nigeria are effective in providing access to Internet in primary and secondary schools although their number is still limited (Adomi \& Kpangban, 2010). In Ghana, ICT has been part of the senior high school curriculum since 2008 (Amenyedzi et al., 2011).

As African governments contemplate investing in MOOCs, access to computers and Internet could initially be through sharing existing computer labs in secondary schools with MOOC students. This means that a needy/ poor student from any village chooses to enrol under a MOOC programme at the nearest public HEI, and studies online by accessing Internet from the nearest secondary school. With this mode of education, the needy students live in their villages and do not pay tuition since access to Internet which translates into access to higher education is provided by government.

It is worth reiterating that sharing computers in secondary schools should only be used as a temporary intervention for enabling access to Internet at the inception of the MOOCs. During this time, regional MOOC enrolment demand can be established and strategic locations earmarked for future construction of MOOC access hubs fully equipped with Internet connectivity, book bank, and reading/ discussion room.

In contrast, low Internet bandwidth is considered the biggest nightmare for access to eresources in Africa. The traditional content access method for MOOCs through high speed Internet and constant connectivity is not realistic to Africa even in the near future following the slow pace in implementing African submarine cables and terrestrial fibre optic networks projects that have slacked for more than a decade. Interestingly in some cases where governments have laid terrestrial fibre optic networks, beneficiary institutions have ignored their responsibility for last mile connections (Wright, 2014). Indeed the high levels of abject poverty still reported in most parts of Africa renders poverty eradication interventions more prominent over Internet access. This points to the need to deliver MOOC content under both online and offline modes and therefore the eLearning platform should be developed in consideration of these capabilities.

The offline platform could be developed similar to the eGranary resource (eGranary is a digital library that provides educational resources via a local area network). In the context of Africa and owing to the fact that a drum is a symbol of communication or knowledge sharing, we propose the eDrum digital library as the metaphor for the offline platform. The eDrum platform should integrate resources from the national eLearning platform, relevant open educational resources, articles from open access journals, and educational video clips from other online sources like YouTube. In addition, the eDrum 
should provide an applications space for graphics, text editing, video recording, games, and animations to enable learners not only to complete their assignments easily but also produce high quality re-usable content. Figure 2 gives a holistic insight of content access options available to a MOOC student, that is, through a MOOC access hub using either online or offline access modes and through communication devices that are commonly available in homes, such as radios, cell phones and televisions.

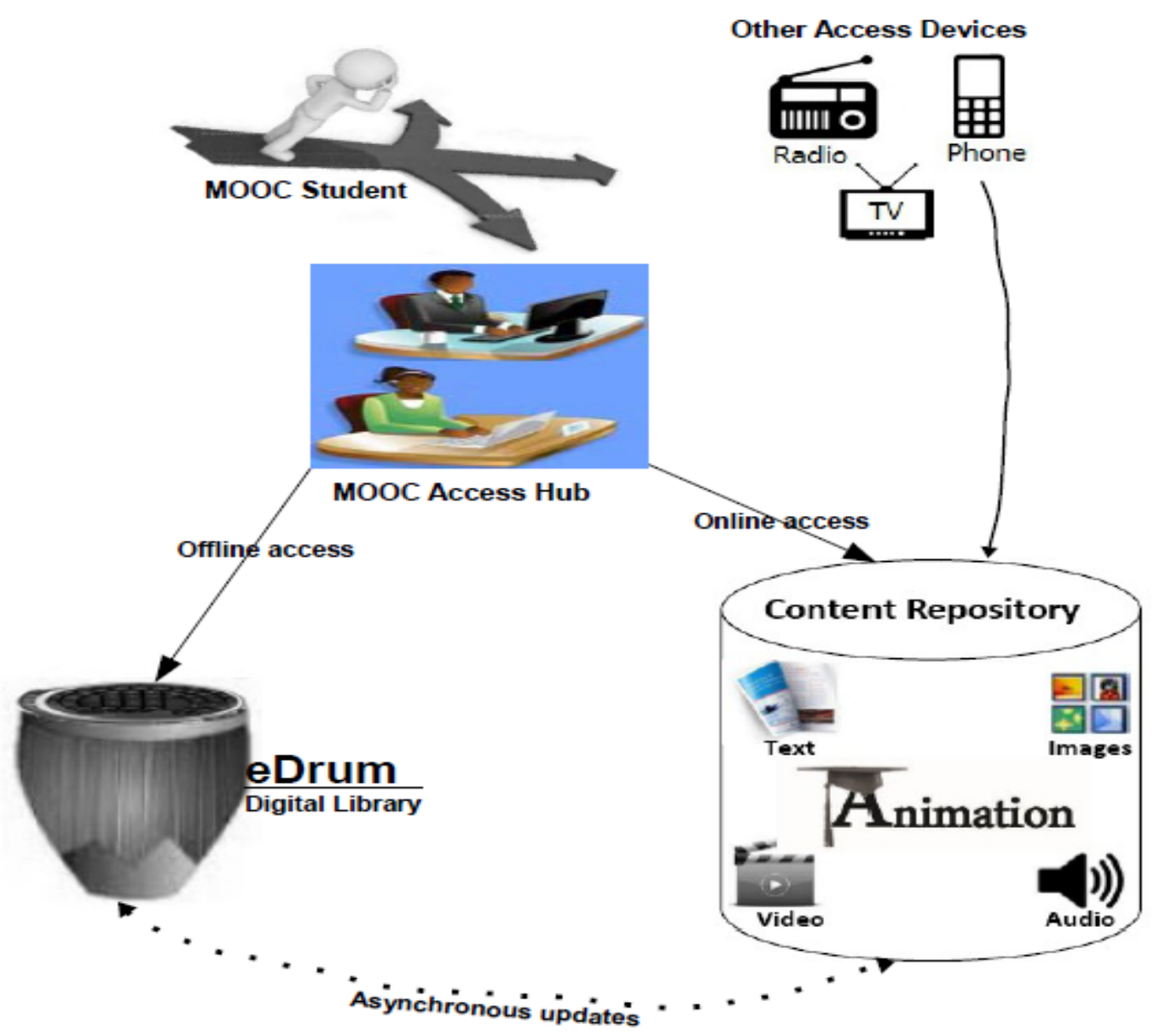

Figure 2. Access options for MOOC students.

As shown in Figure 2, a MOOC student is presented with several access options that suits his/her environment and interest. Apart from using the MOOC access hub resources, the student can learn or participate in an interactive discussion from home using available technologies (cell phones, radio, and TV). This is in line with the growing debate to develop MOOCs that can be delivered on mobile phones which are ubiquitous among African students (Boga \& McGreal, 2014; Gaebel, 2014). 
Aware of the fact that MOOC content is predominantly multimedia, yet Africa is still largely covered by slow or no Internet connection, offline access is an important requirement for the MOOC delivery platform. At the same time, new technologies, such as scalable image and video coding for delivery of multimedia on small displays and HTTP adaptive video streaming (Akhshabi et al., 2012) that enable video transfer in low bandwidth environments, should be implemented at the content repository end. Ultimately, the key requirements for a MOOC delivery platform in the context of resource constraints in Africa are: content delivery technologies for small displays and slow Internet connections, technologies for interactive radio/ television instruction, and technologies for offline access. In light of the aforementioned requirements, a new eLearning platform is necessary since the existing systems, such as Moodle, Coursera, and edX, do not adequately address these requirements and would require significant extentions to effectively function within the contexts of Africa. Moreover, developing a new system that uniquely serves an established need promotes visibility of the developers' institution.

\section{MOOC Implementation Baseline}

As already argued, successful implementation of MOOCs in a developing country would require first and foremost a national coordination secretariat, then a HEI MOOC coordination department. From this common ground, other requirements including content development and programme accreditation, content delivery mechanism, and provision of access to computers and Internet can be met. Table 1 gives the activities and responsibilities distribution for successful implementation of MOOCs in resource constrained environments such as Africa.

Table 1

MOOC Implementation Activities for Developing Countries

Item

1

MOOC curriculum development and accreditation

2 Development of an online and offline eLearning platform for MOOC delivery

3 Development of electronic content corresponding with MOOC curriculum

4 Formation of MOOC coordination units at HEIs

5 Creation of MOOC access hubs at strategic regional centres
Responsibility

Contracted academics from public universities coordinated by national MOOC secretariat

Contracted local firm coordinated by national MOOC secretariat

Contracted academics from public universities coordinated by national MOOC secretariat

HEIs with funding from Education Ministry

National MOOC secretariat with funding from government 
Many of the responsibilities for successful implementation of MOOCs as shown in Table 1 lie with the national MOOC secretariat on behalf of government. Given the varying backgrounds of HE entrants, MOOCs should be designed to support multiple learning styles and again this requires institutional leadership that could be provided by the MOOC secretariat. The design of MOOCs for multiple learning styles, however, is beyond the scope of this paper; literature on this subject can be found in Grünewald et al. (2013).

\section{Lessons for Africa}

Following from the previous discussions, five lessons can be drawn for stakeholders seeking to pursue MOOCs for Africa.

\section{Lesson One: Centrality of Government Funding}

The consolidated insight from Table 1 and Figure 2 can be used by government to perform a cost benefit analysis upon which to execute a MOOC adoption agenda. Fortunately for MOOCs, there is no need for the expensive unit cost per student approach but rather "mass" cost for regional needs. The aspect of one investment serving a large number of students should prompt the respective African governments to consider a phased funding strategy beginning with the regions where the greatest impact is expected.

\section{Lesson Two: Robustness of MOOC Coordination}

The aspect of a central MOOC coordinating secretariat has already been exhaustively discussed in this paper. The robustness implied here is both structural and financial. In terms of structure, the MOOC secretariat should interface with a government ministry for education, HEIs, accreditation agencies, and industry. This would ensure that the functions of a MOOC secretariat are not restricted to enabling access to HE only but also ensuring quality of MOOC programmes and employability of MOOC graduates. The financing of a MOOC secretariat rests primarily on government, that is, the respective African governments should innovatively establish a solid funding mechanism either through charging a nominal functional fee from MOOC students or through direct funding from the central government or both. Once this is achieved, the impact of MOOCs could be realised in a short time.

\section{Lesson Three: Readiness of HEIs}

HEIs are the main drivers of MOOCs at least from the perspective of the developed countries where MOOCs are thriving. The same trend cannot be expected from developing countries whose institutions are heavily underfunded and lack the minimum resources to effectively deliver traditional face-to-face education, let alone online education. If HEIs in Africa are to embrace MOOCs, they must be prepared for it 
through general awareness about MOOCs, establishment or upgrade of multimedia labs, training of staff on the use of modern educational technologies, establishment of MOOC coordination departments, and provision of incentives for MOOC instructors.

\section{Lesson Four: Preparedness of High School Graduates}

The high school curriculum will need to be revised in order to produce students who can engage in MOOCs after secondary education. Some foundational courses currently offered at university level will need to be moved to high school to better prepare students for learning styles supported by MOOCs. Three subjects seem to be most relevant in this respect: communications skills, research methodology, and ICT. While some of these subjects, for example, ICT is already offered in secondary schools as previously discussed, in preparation for MOOCs, a review is necessary irrespective of the prevailing circumstances. For instance, the eDrum platform once developed should be integrated in the secondary school ICT curriculum.

\section{Lesson Five: MOOC Sustainability Strategy}

The concern in promoting the MOOC agenda for Africa lies in the likelihood of its failure. The dilemma surrounding MOOCs in Africa is its reliance on government funding at a time when African governments are more supportive of private than public initiatives. In fact, African governments were quick to implement HE privatisation policy because it relieved them of the burden of financing HE. Viewed differently, integrating MOOCs into the mainstream public education system would definitely ensure its sustainability. In this respect, the existing public student scholarship either through direct funding or student loans or both would be revised and part of the funds allocated to building and running MOOC programmes. At higher education institutional level, cost effective measures for MOOC student support could also be explored. These include:

- Alumni volunteer initiatives, whereby fresh graduates without employment provide instructional support to MOOC students using MOOC access hub facilities as part of their service to community and professional development. In return, the respective HEI awards its volunteer alumni additional community service certificates.

- Instructor outreach. Under the traditional programmes, instructors are engaged in field supervision of students on internship and school practice. During these field engagements, the instructors could be scheduled to interact with MOOC students from the MOOC access hubs without additional costs.

- Requested support, whereby students attached to a MOOC access hub place online requests for face-to-face interaction with their preferred instructors and the HEI MOOC coordination department arranges for these interactions after pooling requests from all its $\mathrm{MOOC}$ access hubs. 


\section{Conclusion}

MOOCs as an educational delivery model is already about half a decade old, but with lukewarm presence in Africa and only one documented case, that is, the "New Economy Skills for Africa ICT" MOOC in Tanzania. In Africa where resources are scarce and HE provision is limited, the need for MOOCs is stronger, yet Africa is the most passive entity in the global MOOC debate on which affordable HE currently lies. At the same time, HEIs in Africa do not seem to be planning for MOOCs let alone in knowledge of MOOCs at institutional level. This paper articulates a flexible roadmap for successful implementation of MOOCs that should allow Africa and the developing countries in general to initiate MOOC programmes using available resources in the short term while scaling-up in the long term. The paper is therefore intended to provoke a new wave of debate and experimentation on mass HE access using MOOCs in the developing countries. What remains to be seen is how the individual African governments and HEIs will react to the insights provided in this paper and previous calls that point to the same direction of affordable HE access for poor students.

The global view of MOOCs as open to anyone who has Internet access is not relevant to Africa where the challenge of Internet access has persisted for over a decade despite implementation of African submarine cables and terrestrial fibre optic cables. The focus of this paper on the design of suitable MOOCs for Africa is therefore timely. Emerging from this paper is the MOOC implementation strategy in the context of limited resources in Africa, clustered under five baseline requirements, including national accredited MOOC curriculum, electronic content development, development of an online and offline eLearning platform, establishment and funding of MOOC coordination units at public HEIs, and establishment of MOOC access hubs at strategic locations. In addition, the sustainability of MOOCs in resource constraint environments of Africa will depend on the robustness of its operational, financial, and technological structures. From the discussions on content access strategies for disadvantaged MOOC students, we can safely conclude that the technological structure centred on eLearning infrastructure that is optimised for low bandwidth and/ or offline accessibility provides a feasible solution to electronic content access challenges in Africa. However, the feasibility of the proposed MOOC operational and financial structures can only be evaluated when MOOCs for Africa are implemented on the basis of these structures. 


\section{References}

Adomi, E., \& Kpangban, E. (2010). Application of ICTs in Nigerian secondary schools. Library Philosophy and Practice, Paper 345. Retrieved from http:// digitalcommons.unl.edu/libphilprac/ 345

Akhshabi, S., Narayanaswamy, S., Begen, A. C., \&Dovrolis, C. (2012). An experimental evaluation of rate-adaptive video players over http. Signal Processing: Image Communication, 27, 271- 287.

Amenyedzi, F. W. K., Lartey, M. N., \&Dzomeku, B. M (2011). The use of computers and internet as supplementary source of educational material: A case study of the senior high schools in the Tema Metropolis in Ghana. Contemporary Educational Technology, 2(2), 151-162.

Boga, S., \& McGreal, R. (2014). Introducing MOOCs to Africa: New economy skills for Africa Program - ICT. Commonwealth of Learning, Canada.

Economides, T. (2013, October). The state of the art in educational technology. Paper presented at the IEEE Global Humanitarian Technology Conference, October 20-23, California, USA.

EDUCAUSE (2013, J une). 7 things you should know about MOOCs. Retrieved from http:// www.educause.edu/library/resources/7-things-you-shouldknow-about-moocs-ii

Eke, H. N. (2010) The perspective of e-learning and libraries in Africa: Challenges and opportunities. Library Review, 59(4), 274- 290.

Emanuel, E. J . (2013). Online education: MOOCs taken by educated few. Nature, 503(342). Retrieved from http://dx.doi.org/ 10.1038/503342a

Gaebel, M. (2014). An update of European University Association's first paper on MOOCs.EUA Occasional Papers. Retrieved from http:// www.eua.be/Libraries/Publication/MOOCs_Update_January 201 4.sflb.ashx

Grünewald, F., Meinel, C., Totschnig, M., \&Willems, C. (2013). Designing MOOCs for the support of multiple learning styles. In Scaling up learning for sustained impact (pp. 371-382). Springer.

Government of Rwanda (2014). Overall review of implementation of World Summit on Information Society Outcomes. Retrieved from www.itu.int/ wsis/review/ inc/docs/rcreports/WSIS10_Country_Reportin g-RWA.pdf 
Hardesty, L. (2012, August). Is MIT giving away the farm? MIT Technology Review. Retrieved from http:// www.technologyreview.com/article/ 428698/is-mitgiving-away-the-farm/

J ordan, K. (2014). Initial trends in enrolment and completion of massive open online courses. International Review of Research in Open and Distance Learning, 15(1), 130-160.

Lewin, K. M. (2004). Mapping the missing link: Planning and financing secondary education in Sub Saharan Africa. Lead Keynote, World Bank Africa Regional Conference on Secondary Education in Africa. Dakar, Senegal.

Materu, P. (2007). Higher education quality assurance in sub-Sahara Africa Status, challenges, opportunities and promising practices. Washington, D.C: The World Bank.

Osokoya, I. O. (2007). Privatization of university education in Africa: Lessons from the theories and practices of the United States of America and J apan. International J ournal of African \&African American Studies, 6(2).

Oyo, B., \&Williams, D. (2014). Towards universal higher education in Uganda using MOOCs. Paper presented at the $9^{\text {th }}$ International eLearning Africa Conference, May 28-30 2014, Kampala, Uganda.

Rodriguez, O. (2013). The concept of openness behind c and x-moocs (massive open online courses). Open Praxis, 5(1).

Pityana, N. B. (2009, J une). Open distance learning in the developing world: Trends, progress and challenges. Keynote, World Conference on Open and Distance Education, J une 7-10, Maastricht, the Netherlands

Wright, C. R. (2014, April). 5 key barriers to educational technology adoption in the developing world. Educational Technology Debate. Retrieved from http:// edutechdebate.org/2014-ict4edu-trends/

(C) Oyo and Kalema

\section{Athabasca University $\mathbf{Z}$}

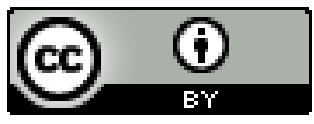

Creative Commons Attribution 4.0 International License 